\section{Revisiting the Importance of Cognition in Information Science}

\author{
John M. Budd
}

School of IS \& Learning Technologies, University of Missouri, USA
Journal of Information Science XX (X) pp. 1-9

(C) The Author(s) 2011

Reprints and Permissions:

sagepub.co.uk/journalsPermissions.nav DOI: 10.1177/016555150000000

jis.sagepub.com

(\$)SAGE

\begin{abstract}
For a considerable amount of time the field of information science has employed its own, as well as the knowledge bases and methods of other fields (with productive results). One field that has been appropriated from has been cognitive science. Cognitive science, however, has been in flux over the last few decades, with different conceptual frameworks assuming ascendance at various times. That dynamic implies that information science should pay close attention to what is occurring in cognitive science in order to investigate the most complex of challenges in information retrieval use, behaviour, and other phenomena. This paper includes a review of the frameworks of cognitive science and suggests that some of the most recent work in that field holds promise for development of thought and inquiry in information science. Understanding of the complex individual processes within human brains, the relationships among thinking communicators, and the relationship of brain and mind, is one of the areas where particular attention should be paid.
\end{abstract}

\title{
Keywords
}

cognition; cognitive science; materialism; epistemology

\section{Background}

For many people, "cognitive science” is a straightforward term with straightforward meaning, but it has problematic aspects. The Cognitive Science Society, founded in 1979, says that it brings together people working in the fields of artificial intelligence, linguistics, anthropology, psychology, neuroscience, philosophy, and education. That is a rather wide-ranging group, but we will see that information does work its way into each field. The term "cognitive science" itself is relatively new, perhaps dating back to the early 1970s, although the study of thinking has its own very long tradition, and uneven genealogy. Before philosophers contemplated thinking as an activity in the brain, they theorized about knowledge. One of the models used for thinking has been examination of logic. Aristotle, for instance, in his Posterior Analytics, said that empirical evidence is not the sole source of knowledge. He worked out a system of logic whereby claims could be analyzed. Reasoning, according to Aristotle, is required to progress from a single perception to a scientific inference of a universal. Plato, in Thaetetus, anticipated Aristotle (although he, through Socrates, did not go as far as Aristotle in developing an analytic system). In disagreeing with Protagoras, Plato has Socrates saying, "Therefore knowledge is not located in immediate experience, but in reasoning about it, since the latter, apparently, but not the former, makes it possible to grasp being and truth” [1, p. 90]. Empirical evidence should not be dismissed; what is to be learned from Aristotle and Plato is that reason should accompany any observation. This paper will explore the impact of studies of cognition on information science (IS). A departure here from some of the work done in IS is the acceptance of several scientific perspectives that, together, contribute to cognitive science. So, the contribution is not solely from fields (valuable though they may be) such as computer science and artificial intelligence. The beginnings will be comprised of background in other fields and then the focus will shift to uses within IS. Finally, attention will be on some particular possibilities that might assist IS, as a discipline, explore new realms of informing, thinking, and 
interactions among people.

\section{Information in information science}

IS, as do other fields, owes a debt to previous evolutionary stages, dating back to the nineteenth century. The debt was acknowledged by Victor Rosenberg (although he explicitly recognized that there are limitations to the received view): "There is no doubt that a large portion of human behavior associated with information is deterministic, even computerlike” [2, p. 264]. Rosenberg's piece indicates the idea that dates from what could be considered the early days of IS. The field was attempting to define its purview and how to approach it. Another early statement was offered by Belkin and Robertson: "IS has up to now regarded [text and its structure] as its major concern; some interest has been shown in [the image-structure of the recipient], but study of this phenomenon has largely been concentrated in the context of psychology or education. [The image-structure of the sender] remains virtually virgin territory” [3, p. 202]. That first phenomenon (the image-structure of the recipient) is integral to any possibility of information processing. A reason for essential character of the image-structure of the recipient is the necessary interpretative action inherent in meaning formation, which is a demonstrably cognitive action. The image-structure of the sender is, as Belkin and Robertson correctly observe, is likewise essential, since it is also an interpretive and cognitive action. These characteristics themselves demonstrate that Rosenberg's stance is insufficient.

IS did not spring full-blown as a field separate and different from everything that preceded it. The influence is evident, for example, in the work of Amos Tversky and Daniel Kahneman. Their writings on probability, logic, and judgment were ground-breaking. Such areas have evident connections with information processing. In one paper they wrote, "Many of the probabilistic questions with which people are concerned belong to one of the following types: What is the probability that object A belongs to class B? What is the probability that event A originates from process $B$ ? What is the probability that process B will generate event A?” [4, p. 1124]. They argued that people have access to a "representative heuristic" that enables the answering of the kinds of questions they asked. The heuristic, according to Tversky and Kahneman, works most of the time, but can result in erroneous judgment from time to time. The principal shortcoming of human behavior is that people tend not to learn from the error situations. Tversky and Kahneman attributed the difficulty to a particular source: "Although everyone is exposed, in the normal course of life, to numerous examples from which these rules could have been induced, very few people discover the principles of sampling and regression on their own. Statistical principles are not learned from everyday experience because the relevant instances are not coded appropriately" [4, p. 1130]. Two things should be noted about their conclusion: (1) human action is determinate to a great extent, so (2) information processing should be a predictable phenomenon if the shortcoming can be overcome. Of course their premise and conclusions can be examined critically. The beginnings of cognitive science are not limits to Tversky and/or Kahnemann. Many other individuals have contributed to the origination and development of the field. To mention just one person, Hilary Putnam, in his earlier work, contributed ideas related to, among other things, the mind-body problem. While his later work repudiates or corrects some of his early thought, the totality of his contribution is valuable.

At times, in IS the idea of information processing takes on a more complicated cognitive tone. Extension of information processing stands on unsure ground; I mean this in an almost literal sense, because those who would problematize information processing in some simple ways also may attempt to fit the problem into the pegs that constitute the traditional stance. In 1985 Herbert Simon wrote a review essay on the progress made in information processing research. His position remained the unsteady mix of instrumentalism, proceduralism, and functionalism (with a few other “isms” thrown in). For example, he wrote, "Models of children's performance in Piagetian tasks which, while they are performance models and not learning models, constitute a first step toward building a developmental theory in information-processing terms” [5, p. 371]. Kinds of information processing, according to Simon, could be successfully and completely modeled by using computers: "If we compare the past five or six years to the comparable period that preceded them, we see a rapid burgeoning of information-processing models of cognition and computer simulation of those models" [5, p. 274]. On the other hand, in reviewing work on information processing, Peter Ingwersen suggests that, "the shift into a situational context assumes consideration of intentionality and processes of interpretation” [6, p. 13]. While Ingwersen has tried to assimilate (among other things) perception and interpretation into information processing and questioned the abilities of computers to capture the unpredictable nature of human cognition and action, he still feels obliged to acknowledge algorithmic processing. Ingwersen does mark the beginnings of a departure from information processing and a transition to awareness of more complex cognitive dynamics.

Ingwersen presents an exhaustive review of the cognitive elements of, particularly, information retrieval work. He includes the principal works published up until about a decade ago. According to Ingwersen, the cognitive approach in 
IS began in about 1977 (giving some sort of start date, even though some scholars had been involved in applications of cognitive science prior to that date) [7]. Also, Fischer, Erdelez, and McKechnie gather many theoretical statements on human information behavior, many of which include some aspects of cognition (and that may mean inclusion of social cognition as well as individual cognition) [8]. There is no need to go over the ground that has already been well ploughed. In more recent years, though, workers in IS have sought to deepen and broaden the scope of cognitive science's applications.

\section{Naturalizing cognition and information}

The cognitive turn (which is not intended as analogous to Richard Rorty's linguistic turn) does not begin and end with information processing (even though the information-processing model has been very influential). All of the aforementioned fields engage cognition in many other ways. Those ways are also sometimes broader than information processing, so it is not easy to point to specific types (and tokens) of research. The work can also be of considerable scope, so it is not always easy to review the work in individual fields. Nonetheless, the period since the 1950s includes a rich, varied, and sometimes disputatious array of work on the cognitive aspects of information, informing, and becoming informed. One theme that runs through the cognitive turn is the effort expended on naturalizing cognition and the mind in general. Naturalizing includes, to a considerable extent, information processing, but it is much more sweeping. A naturalized account of the mind would explain how phenomenal experiences (feeling, believing, attributing, etc.) are products of the external world-experiences that result in responses (and there are natural causes underlying the responses). By no means is everyone examining information and cognition a naturalizer, but those who are have created a body of work that demands attention. Naturalization is a particular and forceful version of materialism. The naturalizers are more likely to come from the fields of philosophy and cognitive science (in the more limited neuroscience and evolutionary linguistics sense). This is nothing more than an observation; the work is still important to studying the creation of the idea of information.

Naturalizers seek certain kinds of explanations for experiences of all sorts, including "thinking” experiences. They do tend to look in particular places for explanations. Some naturalizers, including Fred Dretske, associate the naturalized approach with a representational theory of mind. Dretske maintains, "The thesis, in two parts, is that, plus or minus a bit, (1) All mental facts are representational facts, and (2) All representational facts are facts about informational functions" [emphasis in original] [9, p. xiii]. He tries to strengthen the claim by adding, "Hereafter, when speaking of the Representational Thesis, I will mean the thesis that all mental states are natural representations. This makes the thesis a form of philosophical naturalism” [emphasis in original] [9, p. 8]. His insistence that representation is a material matter is very widely shared; a great many materialists accept at least some postulates of a representational theory. While representation may be accepted (note that I referred to $a$ representational theory), David Papineau takes a divergent stance from Dretske, emphasizing the internal capacity for representation, rather than an external causal stimulus [10, p. 193]. One source of Papineau's disagreement with Dretske (and it is a point that must be considered seriously) is that, while there are surely perceptual causes for representation, there are also non-sensory causes. Reflection, for instance, is a cause of representation according to such a viewpoint, and that case is no less real and material than direct sensory perception. Dretske attempts to deal with the two causes by distinguishing between themdirect causes are "systemic;" conceptual, or non-sensory, causes are "acquired” [9, p. 15]. Systemic representations are biologically fixed, but acquired representations are ontogenetical (related to the development of the individual organism). If, though, ontogeny recapitulates phylogeny, Dretske’s stance encounters some problems.

On the other hand, some people working in the study of the mind adopt a different stance from Dretske. In order to argue, and provide evidence for, the alternative position, its adherents have to do something with what is called "qualia." First, what are qualia? Alvin Goldman refers to qualia as qualitative properties of mental state, "their phenomenological or subjective feelings" [11, p. 87]. One response to the problem, advocated by Daniel Dennett is to dismiss them as imaginary, non-existing [12]. Dismissal would necessitate defining qualia as completely qualitative (in no way material), which would render them outside of any scientific investigation. If qualia are "the ways things seem to us” [13, p. 61], then one may be tempted to see qualia as nothing more than qualitative judgments. However, "the ways things seem to us” is a complex experience. It does, after all, depend on experience and perception. If there is something outside (or even inside for that matter) the body that can be referred to as "things," and there is a first-person experience we can call "seems," then qualia cannot be completely ignored. The very attempt to dismiss or ignore qualia is just a sleight of hand trick (telling the audience to look over there while hiding the qualia so that they appear to disappear). 
Those who do not ignore qualia tend to admit that there is an informational aspect to them. Goldman says that, for those who would adopt any kind of representational functionalism (RF), there may be the need to "grant that the cognitive system uses information about the intrinsic (nonrelational) and categorical (nondispositional) properties of a target state, just as one infers the solubility of a particular cube of sugar from its possession of the intrinsic and categorical properties of sugar” [11, p. 87]. Goldman captures some of the complexity, complexity that Dennett tends to discard. Goldman also clarifies the distinction between computer and brain (equated in some materialist thinking) by emphasizing the nonrelational and nondispositional aspects of qualia. Dennett uses a problematic analogy: when "your kite string gets snarled up, in principle it can be unsnarled, especially if you're patient and analytic. But there's a point beyond which principle lapses and practicality triumphs. Some snarls should just be abandoned” [12, p. 369]. It should be noted that Dennett's work is sweeping and adopts a strongly evolutionary stance; his influence cannot be summarized in its entirety here. Flanagan, though, offers a solution to the problem Dennett creates:

The problem is that two distinct strings have gotten ensnarled. One string is attached to an ordinary box kite that announces that there are certain ways that things seem. The other string is attached to a gaudy kite that ostentatiously flies banners announcing that the ways things seem consist of a set of atomic, non-relational states that possess ineffable properties known deeply, incorrigibly, and exclusively from a first-person point of view [13, p. 62].

In short, ignoring the snarl does not make it go away. The analogy could be beaten to death, but suffice it to say that Flanagan's points rest on refutation of the exclusively first-person character of qualia.

\section{Living in a material world}

Recent work on cognition demonstrates the complexity of the nature of thinking, knowing, and being informed. This work transcends the much more simplistic information processing that has tended to use computers as analogous for the brain (not that this simplistic analogue has disappeared by any means). As research has progressed, new questions have been uncovered, and some of the questions include the role of information. I am not denigrating those thinkers, including Alan Turing, who sought ways to understand thought; the propositions reflection on the thinkers; today's researchers and theorists learned from their models. As is true of all theorizing and much of empirical observation, interpretations can vary. One point that is evident in the previous section is that a particularly stubborn challenge has been locating causation. No one-and certainly no scientists (however one may define "scientist")—would be satisfied with endless reduction. The demise of positivism is sometimes attributed to its inability to extricate itself from reduction, and Willard van Orman Quine attempted to illustrate the impossibility of extrication. So explanation of causes captures the attention of people. The very nature of causation is reason enough to abandon the computer-mind analogue (regardless of the direction of relationship). Human action and thought has numerous complex causes that are overwhelmingly material, but also (in part) are not currently explicable.

Perhaps the most persistent sticking point, frequently recognized by those who share a fundamental materialism, is the nature (or even existence) of mental states. The matter of qualia was discussed above, but the larger issue of concern is whether mental states exist and, if they do, what are they. A defender of the existence of mental states is John Searle. One reason he finds it rather easy to accept that there are mental states is that they are not inconsistent with or contradictory to physical states. In other words, the mental and the physical are not mutually exclusive [14, p. 83]. Searle asserts, in many of his works, that mental states are indeed material, but are marked by first-person qualities. He states his materialism clearly: “Consciousness, in short, is a biological feature of human and certain animal brains. It is caused by neurobiological processes and is as much a part of the natural biological order as any other biological features such as photosynthesis, digestion, or mitosis” [15, p. 90]. Searle does admit, rightly, to some serious challenges to the definition and application of the idea of subjectivity. In one sense subjectivity could be conceived as simply as preference ("I like raspberries better than strawberries") which can vary among people. The more materialist and pertinent (for Searle) conception of subjectivity is that it occurs in, and is perceived by, the individual organism. I feel pain; you do not feel the pain I feel. Even if you empathize with my feeling of pain, what you feel is empathy, not pain. A difficulty here is that, while you may not be feeling a pain that $I$ feel here and now, this does not mean that you are not capable of feeling the same kind of pain. I may have a toothache right now; you may have a toothache at some other time. His conception of subjectivity has an explicit connection with information: "Subjectivity has the further consequence that all of my conscious forms of intentionality that give me information about the world independent of myself are always from a special point of view” [15, p. 95]. I will have more to say about the connection later. 
Several materialist philosophers of mind adopt positions that are similar to Searle's. Alvin Goldman, for example, begins with a hypothesis that mental states are really products of representational functionalism (RF). In response to the hypothesis he identifies some problems that RF would have to overcome, but RF cannot overcome those problems. "Once we acknowledge the need for qualitative properties, however, we realize that we can get a much simpler model of mentalistic self-ascription by dispensing with the functional roles entirely. Why not adopt a very different model in which the concepts of headache, itch, and so forth are representations of qualitative characteristics, not functional roles at all” [11, p. 87]? As we have already seen, Flanagan (1992) posits the existence of classificatory introspection, according to which individuals can learn and thus expand or alter the ways they categorize things (as well as relationships between categories) [10]. Colin McGinn questions whether we can fully comprehend consciousness at all, calling into question straightforward and eliminative materialism. McGinn especially questions physicalism's adequacy to explain introspection, knowledge, and human action. "The fact is that we have no good theory about the nature of mental causation, no model for how reasoning leads to choice. So we try to conceive of this in terms we are familiar with, thus distorting the phenomenon. Mental causation is mysterious, which is not a bit surprising given that consciousness and the self are also mysterious" [emphasis added] [16, p. 167]. Choice and causation cannot be overlayed upon one another, but there are similarities of reasoning that do result in some connection between them. When, for example, an individual seeks explanation for phenomena that are internal (preferences, decisions, pathways, etc.) the ultimate causes are elusive, as McGinn says. Attempts to explain second- and third-person causation are further removed from causal understanding.

\section{Alternatives to eliminativism}

The alternatives to eliminative materialism include a usage and conception of information that are particular to their alternative natures. Flanagan suggests some of the alternatives. In addressing reduction and eliminativism he points out that while science requires words, and in many cases mathematics, to describe and explain (to "show"), painting, sculpture, and music do not [13, p. 268]. They communicate by other means, and a different kind of (strict) processing is needed to appreciate them. To bring his point home, he says, "certain causal processes are best described in terms of information flow" and "we are consciously responsive to information” [13, p. 137]. Moreover, he adds, "Humans are conscious, and the most plausible starting assumption is that we evolved to process information consciously for good biological reasons" [13, p. 139].

Colin McGinn, who, along with David Chalmers, admits to being a "mysterian" when it comes to judging the consciousness of other minds, still maintains that there can be hints as to solutions to the problem. The problem is difficult because, as he says, "I can only be sure that $I$ have consciousness. And the reason for that is that I can be sure I have consciousness without solving the mind-body problem, because of the unique access I have to my own consciousness" [emphasis in original] [16, p. 199]. Even so, the odds are in favor of others being conscious because of the similarities between ourselves and others-similar organic structures, the absence of what we can claim to be consciousness in non-organic things, and the kinds actions that humans do, in face, engage in (refer to the driving example). If one piece of evidence for our own consciousness is introspective reflection, we might ask others to reflect. Another person might be asked why she or he took a particular action. An even more stringent test might rest on what one does with information. If we ask that other person to interpret a poem, or to give an application of a mathematical formula, or to extend an argument presented by an author, the response might be telling. We may agree with McGinn that we still cannot assert anything unequivocally, but we may be able to say that, based on the evidence, the likelihood of the consciousness of others is high.

Now may be a good time to attempt the resolution of some of the problems that have been posed so far. We can begin with eliminativism. David Chalmers present the most straightforward refutation:

Eliminativism about conscious experience is an unreasonable position only because of our own acquaintance with it. If it were not for this direct knowledge, consciousness could go the way of the vital spirit. To put it another way, there is an epistemic asymmetry in our knowledge of consciousness that is not present in our knowledge of other phenomena. Our knowledge that conscious experience exists derives primarily from our own case, with external evidence playing at best a secondary role [emphasis in original] [17, p. 102].

Each of us has direct, first-person consciousness that does not always depend at all on any external stimuli. I think we can take Chalmers's arguments a bit further, though. The first-person consciousness enables one to communicate about what one is conscious of. You could tell me about a memory that just occurred to you; it is your memory and only you have it. But you can offer me some indirect awareness of your memory. I can then question you about it, 
which might lead to additional first-person awareness on your part. Also, you could write about you memory; you could publish your recollection or communicate it through some medium such as a blog. In other words, you do not have to keep your first-person access completely to yourself, and thus I can have first-person access to my perceptions and reactions to what you tell me. There is, of course, an underlying assumption of the existence of language; moreover, there is an assumption that language is shared so as to make a kind of global comprehensibility. Moreover, the ability to have first-person experiences can enhance cognitive responses to the experiences of others.

The kind of exchange just described is possible, in part, because of something that exists prior to our beginning the exchange and, to an extent, prior to your and my existence. Natural language precedes us; it has existed for some time and has been used both internally and communicatively. Those who have access to natural language can create sentences in their own heads that can be intended to express, and even to provide internal explanation for, thoughts, beliefs, and other phenomenal events. By the time you and I come along we have the ability to learn natural language; we also have the capacity to be taught a natural language by someone else. That act of teaching and learning is an informative one. The informative aspect can be taken as evidence simultaneously of first-person consciousness and of a sharing of conscious processes that are components of the physical being of humans. The particular teacher cannot have direct access to the consciousness of the particular learner, but the teacher does have first-person experience of learning. Flanagan says, "there is absolutely no reason why a naturalist cannot both acknowledge the existence of subjectivity and view getting an accurate description of it as part of the overall project of understanding an accurate description of it as part of the overall project of understanding human nature” [13, p. 92]. The so-called problem of other minds is thus re-shaped. There is indeed a problem for each of us in that we cannot have first-person awareness of other people's minds. All the while, though, each of us understands what it is like to have first-person experience of our own consciousnesses. The latter enables us to communicate with one another, to inform and to be informed.

\section{Where does IS go now?}

The question, naturally, cannot be answered absolutely and completely. The foregoing, though, provides indications of direction and frameworks for future work. What follows is some elaboration on possibilities. As has been noted, cognition and cognitive processes have featured in IS work for some time. I will suggest that the first task for researchers in IS will be to exercise conceptual transcendence. The actual application of this mode of thought is simpler than its label. It we take behaviorism as the first obstacle to transcend we can rely on a wealth of work that helps us with the task. For example, Harnad summarizes many of the particular operations through which we should proceed. To begin with, behaviorism never answered a key question that it asked: "How do we have the behavioral capacity that we have? What makes us able to do what we can do?” [18, p. 246]. Further, behaviorism is unable to explain the act of naming, which has nothing to do with responding to stimuli and everything to do with categorizing [18, p. 249]. It is not necessary here to repeat the shortcomings of behaviorism; inquiry in IS has successfully transcended behaviorism as a fatally flawed idea. Behaviorism has not entirely disappeared from many fields, but, as a legitimate framework, it is demonstrably dismissible.

The next conceptual framework to transcend is information processing (in the very narrow sense of mere computation). [N. B.: Transcending information processing or computation does not entail complete abandonment of information processing or computation; there remain reasons to think that some functioning of consciousness entails these mechanisms. Transcendence does mean, though, that they are not sufficient. The flaws have been noted above.] A metaphoric description of the information processing model is suggested by neuroscientist Steven Rose:

It took the experience of Stalinism in the former Soviet Union and Fordism in capitalism to show that command economies don't work. But nor can neural systems in which information passes upwards and inflexible commands return downwards. Instead, the brain operates like a classical anarchistic commune in which the semi-autonomous work of each distinct region contributes harmoniously to the whole: from each region according to its abilities to each according to its needs [19, p. 154].

The flaws of an information-processing model are also described succinctly by Searle: "In the case of the brain, none of the relevant neurobiological processes are observer relative (though of course, like anything, they can be described from an observer-relative point of view) and the specificity of the neurophysiology matters desperately” [20, p. 104].

A third conceptual framework-connectionism—should be transcended. The notion of the neural network is a key component of connectionism. In some applications, this framework is limited to the translation of numerical input representations into numerical output representations [see 21, p. 9]. It is, in particular, this very limited conception of 
connectionism that should be transcended. For other applications, the aim is to resolve the translation of symbolic representations. Connectionism is actually a fairly close relative of information processing, as described above; connectionism attempts to simplify symbol-real distinction by proposing the network nature of processing. A challenge, to reiterate, is the absence of symbolic representation translation and interpretation. R. A. Wilson puts his finger on the problem: "On this view of representation, what is in the head are not discrete symbols, each encoding their own piece of information, but less content-laden nodes which, in combination with the connection strengths linking them, collectively represent information about the world” [22, p. 148]. In short, the difficulty with narrow connectionism tends to rest with presumptions of semantic similarity among ideas and speech.

There is a piece of common ground that these frameworks share; the assumption that the purpose of the brain/mind is to solve problems that are predefined (that come from outside the subject) [see 21, pp. 9-10]. A considerable amount of the inquiry in IS (though by no means all) has fallen prey to this problem. It is not that nothing can be learned by presenting people with problems; the field of psychology (as well as IS) has progressed by applying this methodology. The potential for learning is necessarily limited, though. The path for IS can benefit by transcended the earlier stages of cognitive science. "Transcending" should be emphasized here because it is meant to imply having passed through the earlier stages - so the contributions that cognitive science can make to study in IS are substantial and directly related to some of the most pressing issues in the field. Only a few examples will be offered here by way of contrasting the past with the potential future and pointing to some possibilities.

A strain of research in IS could pay close attention to developments in neuroscience, but should at the same time be sensitive to pitfalls that have been the bane of both neuroscience and philosophy. For the strain to be productive, people who already have some background in neuroscience-related work or people who can investigate that work would have to be involved. Neuroscience is concerned primarily with the physical structure of the brain, but as Rose reminds us, that knowledge can help us reach a more complete understanding of the mind (Rose is a materialist who is open to discovery of complex thought that is not limited to computation) [19]. He emphasizes that, in order to comprehend ourselves as mindful beings we have to explore the history of our development (our evolution) and the history of the cognitive sciences [19]. He also recognizes that many large challenges still face cognitive science and, extending this line argument to IS as well: "Thus the apparently seamless process of observing, evaluating, and choosing between images based on past experience involves multiple brain regions, not necessarily connected via simple synaptic pathways. Achieving such coherence is called 'binding', and, as I have said, is the central theoretical problem for twenty-first-century neuroscience” [19, p. 157]. Rose makes one point that all researchers delving into the cognitive elements of IS should attend to the brain operates, not just according to the location (the places in the brain where certain activities occur), but also according to time (when a human subject experiences things, thus helping to shape the dimensions of experience) [19, pp. 158-59]. Rose's work marks only one neuroscientific possibility; others can certainly be examined.

The need to augment what can be learned from neuroscience with psychological background and its inclusion in empirical inquiry cannot be overstated. Bennett and Hacker emphasize this importance: "What [neuroscience] cannot do is replace the wide range of ordinary psychological explanations of human activities in terms of reasons, intentions, purposes, goals, values, goals, rules and conventions by neurological explanations” [emphasis in original] [23, p. 3]. The entire being a person perceives something, not just the brain (although the perception and, especially, making sense of the perception, is not possible without the brain). In the field of IS, Hjørland has presented many conceptual and empirical works that have followed the prescription of Bennett and Hacker. One example is his recent expansion on the concept of relevance. In that piece he affirms Saracevic's idea of thirty-five years earlier [24] that the "subject knowledge view" - one that includes a pragmatic theory of knowledge that incorporates the needs of people and their evaluations of documents - is by far the most fruitful alternative to the received positivist view of relevance characterized by, among other works, the Cranfield studies [25]. William James, defining pragmatic knowledge, says, "All that the pragmatic method implies, then, is that truths should have practical consequences" [26, p. 52]. He further states, anticipating the realism that has been articulated more recently, “That reality is 'independent' means that there is something in every experience that escapes our arbitrary control” [26, p. 69]. John Dewey’s thought tends to follow that of James. A necessary accompaniment to Hjørland and Saracevic is avoidance of the "mereological fallacy" [23, pp. 68-107). This entails mistaking the operation of parts for the whole; in IS this could mean an undue attention to components of an information system, on a searcher's specific terms, on individual pieces of a retrieval model, or on parts of the brain. Individuals such as Brenda Dervin, Nicholas Belkin, and T. D. Wilson in IS have provided some guides for work that stays clear (for the most part) of the mereological fallacy.

The mereological fallacy probably requires a bit more explication. There can be a tendency in the study of any human action, including human information behavior as an example, to separate what appear to be components of the 
action. A person goes through a lot, cognitively and behaviorily, to retrieve and evaluate information. It is indeed the case that that person has to do certain things to retrieve the information (conduct a search in a database, for instance). Cognitively, though, there isn't a separability into discrete acts. The evaluation of a document (writ large) may lead to the person's thinking about the question or problem at hand in a somewhat altered way, but the totality of the action is what can, and should, be examined. Document A may inform the person about something hitherto unknown; that may lead the person to re-evaluate other documents and/or to assess additional documents in light of what is now known. At the heart of this example of possible inquiry is the fundamental cognitive aspect of the person's action. That is what further work in IS can embrace.

A related (to Hjørland's conception) potential strain of research entails the manifestations of individual and social (or collective) cognitive actions. Yet another challenge that cognitive science and IS face is the environmental effects on the human mind (and a major environmental effect is the society in which one lives). R. A. Wilson, a cognitive scientist, elucidates how different disciplines can limit their scope of inquiry, perhaps to the point of missing bigger pictures:

Within evolutionary biology, human agents are conceived as animals with a phylogenetic history and a particular range of ecological niches. Within anthropology, human agents are interpreters of meaning and creators of culture. Within cognitive science, they are the locus for computational programs and modules. Within economic, rational decisionmakers [sic], optimizers of utility [22, p. 5].

R. A. Wilson argues in favor of the individualistic position, claiming that a purely societal analysis can reify the actions of the individual. His warning has merit, but the opposite-ignoring society as an influence on individual thought and action - is likewise problematic. It is here that Goldman's [27, 28] work on social epistemology can meld the internal and external forces in a way that expands understanding of human thinking and being. Goldman is bold enough to say, "This is how I conceive of epistemology: as a discipline that evaluates practices along truth-linked (veritistic) dimensions. Social epistemology evaluates specifically social practices along these dimensions” [11, p. 69]. I agree with his fundamental definitions. Placing evaluation at the focal point unites cognition and information. As an example, Goldman includes testimony - the words of others that we can hear/read and evaluate. He (1999) points out that, "Four stages of testimony-related activity are relevant to the ultimate level of socially distributed knowledge: (1) discovery, (2) production and transmission of messages, (3) message reception, and (4) message acceptance” [11, pp. 103-04].

A component of the melding of the internal and the external, the individual and the social, in the way people think is the use of language. To speak is to engage in a cognitive process (as is to hear). Language may be the source of the greatest disagreement in a variety of fields that includes linguistics, psychology, sociology, anthropology, literary study, cultural studies, and IS (and probably others). Some researchers focus on grammar, some on syntax, and some on semantics. The kinds of verbs people use and the ways they use them can indicate a substantial amount about thought [see 29]. For example, if someone has a tendency to employ factives, that person is communicating (or attempting to communicate) certainty regarding what is claimed. The most famous/infamous use of a factive is George W. Bush's sixteen words in his 2003 State of the Union address: “The British Government has learned that Saddam Hussein recently sought significant quantities of uranium from Africa.” The statement implies knowledge, which can affect other cognitive processes that could influence other propositions and conclusions. Study in IS could examine factive statements made by individuals, for instance, and the claimed sources for the certainty. Such study certainly need not be limited to formal statements made by public figures (although that could be the focus of particular projects); other speech acts could be examined, as Hannabus points out [30].

The options and possibilities just outlined depend on the critique that has formed the bulk of this paper. That is, progress depends on transcending limitations that some thought and work in cognitive science has left us with. But every discipline travels through stages, embracing them for a time, then questioning them, and perhaps abandoning them altogether. The message of this paper is that, while IS critically incorporates or appropriates from other disciplines (almost all disciplines appropriate from other disciplines), effective incorporation includes understanding of the questions IS asks - relies upon awareness of current work in other disciplines. It also depends on awareness of the critical assessment of that work. Rose offers a warning that all researchers must heed, and that IS must accept, since the warning actually has few limits: “The sad fact is that even within the neurosciences, we don't all speak the same language, and we cannot yet bridge the gap between the multiple levels of analysis and explanation, of the different discourses of psychologists and neurophysiologists" [19, p. 211]. One thing that has been left to one side through most of the present examination is the role of truth in IS and in any study of information as cognitive phenomenon. The reason for the absence has nothing to do with the importance of truth; in fact, it is vitally important. For more on the 
place of truth within a definition of information, see [31]. The cognitive aspect of IS is large; the present work is one contribution to the larger discourse.

\section{References}

[1] Plato. Thecetetus, J. McDowell (trans.) (Clarendon Press, Oxford, 1984).

[2] V. Rosenberg. The scientific premises of information science. Journal of the American Society for Information Science 25 (4) (1974) 263-263.

[3] N.J. Belkin and S.E. Robertson, IS and the phenomenon of information, Journal of the American Society for Information Science 27 (4) (1976) 197-204.

[4] A. Tversky and D. Kahneman, D. Judgment under uncertainty: Heuristics and biases, Science, 185 (4157) (1974) 1124-1131.

[5] H.A. Simon, Information-processing models of cognition, Journal of the American Society for Information Science 32 (5) (1985) 364-377.

[6] P. Ingwersen, Cognitive perspectives of information retrieval interaction elements of a cognitive IR theory, Journal of Documentation 52 (1) (1996) 3-50.

[7] Ingwersen, P., Cognitive information retrieval, Annual Review of Information Science and Technology 34 (1999) 3-52.

[8] K. E. Fischer, S. Erdelez and L.E.F. McKechnie (eds.) Theories of Information Behavior (Information Today, Medford, NJ, 2005).

[9] F. Dretske, F., Naturalizing the Mind (MIT Press, Cambridge, MA, 1995).

[10] D. Papineau, Thinking about Consciousness (Oxford University Press, Oxford, 2002).

[11] A.I. Goldman, Philosophical Applications of Cognitive Science Westview Press, Boulder, CO, 1993).

[12] D.C. Dennett, Consciousness Explained (Little, Brown, Boston, 1991).

[13] O. Flanagan, Consciousness Reconsidered (MIT Press, Cambridge, MA, 1992).

[14] J.R. Searle, Consciousness and Language (Cambridge University Press, Cambridge, 2002).

[15] J.R. Searle, The Rediscovery of the Mind (MIT Press, Cambridge, MA, 1992).

[16] C. McGinn, The Mysterious Flame: Conscious Minds in a Material World (Basic Books, New York, 1999).

[17] D.J. Chalmers, The Conscious Mind: In Search of a Fundamental Theory (Oxford University Press, New York, 1996).

[18] S. Harnad, Cohabitation: Computation at seventy, cognition at twenty. In D. Dedrick and L. Trick (eds.), Computation, Cognition, and Pylyshyn (MIT Press, Cambridge, MA, 2009).

[19] S. Rose, The Future of the Brain: The Promise and Perils of Tomorrow's Neuroscience (Oxford University Press, Oxford, 2005).

[20] J.R. Searle, Philosophy for a New Century: Selected Essays (Cambridge University Press, Cambridge, 2008).

[21] E. Thompson, Mind in Life: Biology, Phenomenology, and the Sciences of Mind Belknap Press of Harvard University Press, Cambridge, MA, 2007).

[22] R.A. Wilson, Boundaries of the Mind: The Individual in the Fragile Sciences (Cambridge University Press, Cambridge, 2004).

[23] M.R. Bennett and P.M.S. Hacker, Philosophical Foundations of Neuroscience (Blackwell, Oxford, 2003).

[24] T. Saracevic, Relevance: A review of and a framework for the thinking on the notion in information science, Journal of the American Society for Information Science 26 (13) (1975) 321-346.

[25] B. Hjørland, The foundation of the concept of relevance. Journal of the American Society for Information Science and Technology 61 (2) (2010) 217-237.

[26] W. James, The Meaning of Truth (Prometheus Books, Amherst, NY, 1997).

[27] A.I. Goldman, Knowledge in a Social World (Oxford University Press, Oxford, 19).

[28] A.I. Goldman, Pathways to Knowledge: Private and Public (Oxford University Press, Oxford, 2002).

[29] S. Pinker, The Stuff of Thought: Language as a Window into Human Nature (Viking, New York, 2007).

[30] S. Hannabus, Dialogue and the search for information Aslib Proceedings 41 (3) (1989) 85-98.

[31] J. Budd, Meaning, truth, and information: Prolegomena to a theory, Journal of Documentation 67 (1) (2011) 5674. 